EVIDENCE BASED PUBLIC HEALTH POLICY AND PRACTICE

\title{
Monitoring community responses to the SARS epidemic in Hong Kong: from day 10 to day 62
}

\author{
J T F Lau, X Yang, H Tsui, J H Kim
}

J Epidemiol Community Health 2003;57:864-870

See end of article for authors' affiliations ......................

Correspondence to: Dr J T F Lau, Centre for Epidemiology and Biostatistics, 5/F, School of Public Health, Prince of Wales Hospital Shatin, NT, Hong Kong;

jlau@cuhk.edu.hk

Accepted for publication 14 August 2003

\begin{abstract}
Study Objective: To report the evolution in perceptions and behaviours of the general public in response to the severe acute respiratory syndrome (SARS) epidemic in Hong Kong.

Design: Ten similar and sequential telephone surveys were conducted during outbreak of SARS, which are classified as belonging to the first and second phases of the epidemic.

Setting: Hong Kong, China.

Participants: 1397 Hong Kong residents between 18 and 60 years of age.

Main outcome measures: Perceptions and behaviours to SARS and its prevention.

Results: Most of the respondents believed that SARS could be transmitted via direct body contact and droplets. About half of respondents believed that SARS was curable, which increased in the initial phase and decreased in the second phase. Perceived chance of infection was low (9\%) but fear of infection in public places was high (48\%). Perceived efficacy of hygiene measures (wearing a mask: $82 \%$, hand washing: 93\%, and home disinfection: 75\%) remained high in both phases and the perceived efficacy of avoiding crowded place, and using public transportation, etc, increased initially and decreased in the second phase. In parallel, use of the three hygiene measures increased significantly in the first phase and remained high for wearing a mask and washing hands in the second phase. Percentages of people avoiding crowded place and public transportation significantly increased initially and decreased in the second phase.

Conclusion: SARS related perceptions and behaviours evolved rapidly during the epidemic and Hong Kong residents quickly adopted appropriate SARS prevention measures. Timely dissemination of information seems effective in public health crises management.
\end{abstract}

$\mathrm{T}$ he first outbreak of the severe acute respiratory syndrome (SARS) epidemic in Hong Kong occurred in the Prince of Wales Hospital (PWH) on 10 March 2003. ${ }^{1}$ The second large scale outbreak occurred in the community around 26 March, in which a total of 321 residents in the Amoy Gardens were affected. ${ }^{2}$ On 29 March, all classes in all schools in Hong Kong were suspended. On 31 March, all block E residents of the Amoy Gardens estate were quarantined at home and all close contacts of SARS patients in Hong Kong were required to be examined in designated clinics. On 1 April, all block E Amoy Gardens estate residents were further moved to two quarantine camps. The number of newly reported cases also increased from 25 on 23 March to a peak of 80 cases per day on 31 March. On 2 April, the World Health Organisation issued a travel advisory warning for Hong Kong. ${ }^{3}$ The period of time before 1 April can therefore be seen as the escalating phase of the SARS epidemic in Hong Kong. The situation improved gradually thereafter. The number of newly reported cases declined to 28 on 10 April and became fewer than 10 cases per day after 3 May. As of 25 May, there were 1725 cases $^{4}$ and as of 1 August 2003, there were 1755 cases with the last probable SARS case reported on 11 June 2003. ${ }^{5}$ Classes were resumed in all universities on 14 April, in secondary schools on 22 and 28 April, and, in primary schools on 12 and 19 May. On 23 May, the WHO lifted the travel advisory warning against Hong Kong. ${ }^{6}$ Therefore, the period after 1 April period can be seen as the second phase of the epidemic.

Knowledge, attitudes, behaviours, and practice studies are used to investigate patterns of community responses to the development and prevention of a disease. ${ }^{7-11}$ SARS is a new disease and the interaction of public attitudes, belief, and behaviours would determine the effectiveness of the preven- tion of the disease. The study aims to report the evolution and changes in attitudes, knowledge, and behaviours of Hong Kong residents in response to the public health crisis during the two phases of the epidemic.

\section{METHODS \\ Respondents}

The study population includes all Chinese Hong Kong residents who were between 18-60 years of age. Telephone surveys using a structured questionnaire and random telephone numbers selected from up to date telephone directories were conducted. Almost 100\% of the Hong Kong residents have telephones at home (Hong Kong Office of the Telecommunications Authority, personal communication, 28 January 2000). Interviews were conducted between 600 pm to $1000 \mathrm{pm}$ to avoid over-representation of non-working people. The household member whose birthday was closest to the interview date was invited to join the study. For noncontacts, at least three calls were made on different dates of the week and at different hours (follow up calls were made during daytime of weekends).

Since the PWH outbreak, 10 rounds of surveys were carried out on 21 March (day 10 since the PWH outbreak, $\mathrm{n}=80$ ), 22 March $(n=156), 23$ March $(n=156), 24$ March $(n=91)$, and 28 March $(n=66)$, 1 April $(n=169), 8$ April $(n=159)$, 11 April $(n=155)$, and 24 April $(n=165)$, as well as on 12 May (day 10 to 62 since the PWH outbreak). Among contacted households with an eligible potential respondent

Abbreviations: SARS, severe acute respiratory syndrome; $\mathrm{PWH}$, Prince of Wales Hospital 
answering the call $(\mathrm{n}=2424)$, there were 1397 agreeing and 1027 refusing to participate. The response rate was thus $57.6 \%$ (1397 of 2424).

Ethics approval was obtained from the ethics committee of the Chinese University of Hong Kong and verbal informed consent was obtained from all respondents of the survey.

\section{Measurements}

Respondents were requested to provide information on the sources of SARS infection, and on their SARS related perceptions and behaviours (see table 2 to 5 ). While most of the questionnaire items were asked on all dates of the survey, a subgroup of items were asked only in the early part of the survey and another subgroup was only asked in the later dates of the survey to maintain the length of the interview to less than 15 minutes. The dates that specific questionnaire items were asked are listed in the relevant tables and text.

\section{Statistical methods}

The distributions of responses were tabulated and were tested using $\chi^{2}$ test for trend in the two phases of the epidemic (up to and after 1 April). The differences between the two phases were also tested by $\chi^{2}$ test. Odds ratios were derived by using multiple logistic regression models. Forward stepwise selection of variables was used to identify factors predictive of different types of preventive behaviours. SPSS for Windows Release 11.0.1 (SPSS Inc, Chicago, USA) was used to analyse the data and $\mathrm{p}$ values less than 0.05 were considered to be significant.

\section{RESULTS}

\section{Background characteristics}

Of the 1397 Hong Kong residents who participated in the surveys, there were slightly more men $(51.4 \%)$ than women (49.4\%). Respondents of 18-29, 30-39, 40-49 years of age accounted for $26.7 \%, 25.2 \%$, and $28.2 \%$, respectively, and $20 \%$ of respondents were aged 50-60 years. Most respondents received an education between form 4 (equivalent to 10 years of formal education) and form 7; $27.1 \%$ of them had tertiary education and $28.3 \%$ had an educational level below form 4. Variations in the distribution of gender, age, education levels, and occupation type among the respondents were not significant between the surveys.

\section{Seeking SARS related information}

The respondents were also asked whether they were closely following new developments of the SARS outbreak everyday and what their sources of information were. These questions were asked only in the first three surveys and were dropped because of the length of the questionnaire. The results show that during the initial phase of the epidemic (21 to 24 March), $90.5 \%$ of the respondents were actively seeking information about SARS on a daily basis. Of these respondents, $89.8 \%$ were obtaining information from television; $71.1 \%$ were obtaining information from newspapers, and $27.1 \%$ received their information from radio. Less than $10 \%$ were getting SARS information from medical professionals $(4.9 \%)$, friends $(8.7 \%)$, or from the internet (3.3\%).

\section{Perceived modes of transmission, curability, and fatality of SARS}

As summarised in table 1, most of the respondents believed that this disease could be transmitted via direct body contact with SARS patients and via respiratory droplets $(84.4 \%, 97 \%$, $\mathrm{p}>0.05)$. Percentages of respondents believing that SARS could be transmitted via aerosol and articles touched by patients, increased in the first phase and levelled off in the

Table 1 Knowledge and attitudes related to modes of transmission, curability, fatality, and susceptibility of SARS

\begin{tabular}{|c|c|c|c|c|c|c|c|c|c|c|c|c|c|c|}
\hline & \multicolumn{10}{|c|}{ Date of interview } & \multirow[b]{3}{*}{ All } & & & \\
\hline & \multicolumn{5}{|c|}{ Initial phase } & & \multicolumn{4}{|c|}{ Second phase } & & & & \\
\hline & 21.3 & 22.3 & 23.3 & 24.3 & 28.3 & 1.4 & 8.4 & 11.4 & 24.4 & 12.5 & & \multicolumn{3}{|c|}{$p$ Value $\nmid p$ Value $\ddagger p$ Value $\S$} \\
\hline $\begin{array}{l}\text { New SARS cases on the previous } \\
\text { day } \\
\text { Mode of transmission }\end{array}$ & 20 & 32 & 20 & 25 & 51 & 80 & 41 & 28 & 24 & 4 & & & & \\
\hline $\begin{array}{l}\text { Direct body contact with patients } \\
\text { (\% very likely/likely) }\end{array}$ & 80.5 & 81.8 & 81.8 & 67.7 & 87.0 & 84.3 & 87.3 & 90.3 & 86.7 & 83.7 & 84.8 & 0.350 & 0.856 & 0.053 \\
\hline Droplets (\%very likely/likely) & 92.1 & 97.4 & 95.6 & 98.5 & 97.6 & 97.89 & 96.8 & $98.1^{* *}$ & 94.5 & $97.7-9$ & 96.8 & 0.216 & 0.683 & 0.659 \\
\hline Aerosols (\%very likely/likely) & 39.0 & 40.7 & 40.0 & 58.5 & 46.7 & 48.4 & 37.2 & 34.4 & 30.3 & 30.2 & 39.5 & 0.181 & $<0.001$ & $0.003-9$ \\
\hline $\begin{array}{l}\text { Articles touched by patients } \\
\text { (\%very likely/likely) }\end{array}$ & 45.5 & 39.3 & 46.7 & 47.7 & 71.0 & 71.49 & $63.5^{\circ}$ & 70.89 & 69.79 & $58.1^{*}$ & 60.9 & $<0.001$ & 0.316 & $<0.001^{\star * *}$ \\
\hline $\begin{array}{l}\text { Environment contamination } \\
\text { (\%very likely/likely) }\end{array}$ & - & - & - & - & - & - & 56.1 & 55.2 & 60.6 & 55.2 & 56.8 & - & 0.917 & - \\
\hline SARS is curable? (\%Yes) & 48.6 & 38.7 & 34.4 & $30.8 \S \S$ & 54.0 & 66.3 & 57.0 & 61.8 & $25.8 \S \S$ & 37.3 & 47.1 & $<0.001$ & $<0.001$ & $0.015^{\star \star \star}$ \\
\hline $\begin{array}{l}\text { SARS is fatal ?(\%Yes) } \\
\text { Susceptibility to SARS }\end{array}$ & 76.3 & 74.8 & 72.2 & 66.7 & $55.0 \S \S$ & 35.0 拉 & $=31.6 \neq \ddagger$ & $31.6 \pm \ddagger$ & $59.8 \S \S$ & $45.6 \S \S$ & 51.6 & $<0.001$ & $<0.001$ & $<0.001 \oplus \uparrow$ \\
\hline $\begin{array}{l}\text { Perceived chance of infection for } \\
\text { oneself (\%very large/large) }\end{array}$ & 3.9 & 9.2 & 8.8 & 11.1 & $14.3^{* *}$ & 12.4 & 7.0 & 7.1 & 7.3 & 4.7 & 8.7 & 0.124 & 0.038 & 0.126 \\
\hline $\begin{array}{l}\text { Perceived chance of infection for } \\
\text { family members (\%very large/large) }\end{array}$ & 6.4 & 11.8 & 7.7 & 7.9 & 11.9 & 11.4 & 9.5 & 10.4 & 9.7 & $1.2 \pm \ddagger$ & 9.0 & 0.430 & 0.017 & 0.318 \\
\hline $\begin{array}{l}\text { Worried about oneself and family } \\
\text { members being infected (\% much } \\
\text { worried/worried) }\end{array}$ & 37.2 & 41.7 & $19.8 \S \S$ & 42.4 & 43.8 & 33.5 & 28.5 & 34.2 & 38.8 & $18.0 \S \S$ & 33.6 & 0.524 & 0.291 & $0.003-9$ \\
\hline $\begin{array}{l}\text { Fear of contracting the virus in } \\
\text { public places (\% much scared/ } \\
\text { scared) }\end{array}$ & - & - & - & - & 55.6 & 52.4 & 53.2 & 50.3 & $43.6+\dagger$ & $35.5 \S \S$ & 48.4 & 0.548 & 0.001 & 0.040 ฯ \\
\hline
\end{tabular}

†For comparison from $21 / 3$ to $1 / 4$ and derived from two sided linear by linear $\chi^{2}$ test; $\neq$ For comparison from $1 / 4$ to $12 / 5$ and derived from two sided linear by linear $\chi^{2}$ test; $\S \chi^{2}$ test for comparisons between phase 1 (not including $1 / 4$ ) and phase $2 ;{ }^{*},-$ and ${ }^{* *} O R \geqslant 1$ and $<2, \geqslant 2$ and $<4$, $\geqslant 4$, respectively and $p<0.05$, for comparison with the reference $(21 / 3)$ or the first column of data while controlling for age, gender, and levels of education; $†+, \S \S$, and $\ddagger \pm O R \geqslant 0.5$ and $<1, \geqslant 0.25$ and $<0.5,<0.25$, respectively, and $p<0.05$, for comparison with the reference (21 Mar) or the first column while controlling for age, gender, and levels of education; - data not collected for those rounds of survey; $\uparrow$ significantly increased from the initial phase to the second phase ( $p<0.05$ by $\chi^{2}$ test); ${ }^{* * *}$ significantly decreased from the initial phase to the second phase $\left(p<0.05\right.$ by $\chi^{2}$ test). 
Table 2 Perceived risk of SARS transmission at different places

\begin{tabular}{|c|c|c|c|c|c|c|c|c|c|c|c|c|c|c|}
\hline & \multicolumn{10}{|c|}{ Date of interview } & \multirow[b]{3}{*}{ All } & \multirow[b]{3}{*}{ p Valuet } & \multirow[b]{3}{*}{ p Valueł } & \multirow[b]{3}{*}{ p Value§ } \\
\hline & \multicolumn{5}{|c|}{ Initial phase } & \multirow[b]{2}{*}{1.4} & \multicolumn{4}{|c|}{ Second phase } & & & & \\
\hline & 21.3 & 22.3 & 23.3 & 24.3 & 28.3 & & 8.4 & 11.4 & 24.4 & 12.5 & & & & \\
\hline $\begin{array}{l}\text { Working in office (very } \\
\text { high/high)§, }\end{array}$ & 21.8 & 23.8 & 27.5 & 29.7 & 32.0 & 33.7 & 17.7 & 23.2 & 24.2 & 11.6 & 24.3 & 0.031 & 0.004 & $0.033 \uparrow 9$ \\
\hline $\begin{array}{l}\text { Using public transportation } \\
\text { vehicles (very high/high)§ }\end{array}$ & 40.0 & 52.0 & 50.5 & 57.89 & 66.99 & $62.7 \uparrow$ & 38.0 & $54.8^{*}$ & 48.5 & 38.4 & 51.4 & 0.004 & 0.077 & 0.016 ब \\
\hline $\begin{array}{l}\text { Eating in restaurants(very } \\
\text { high/high) }\end{array}$ & 33.8 & 41.8 & 44.0 & 48.4 & $53.3-$ & 45.7 & 26.6 & 29.7 & 32.7 & 25.0 & 37.5 & 0.335 & 0.009 & $<0.0019 \uparrow$ \\
\hline $\begin{array}{l}\text { Walking in the street (very } \\
\text { high/high) }\end{array}$ & 11.7 & 15.0 & 18.7 & $24.6 \uparrow$ & 19.5 & 15.1 & 5.7 & 7.1 & 7.9 & 6.4 & 12.2 & 0.744 & 0.055 & $<0.0019 \uparrow$ \\
\hline Using lifts (very high/high) & $T-$ & - & - & - & - & 55.1 & $37.3 \S \S$ & 44.5 & $32.1 \S \S$ & $30.8 \S \S$ & 40.2 & - & $<0.001$ & - \\
\hline $\begin{array}{l}\text { Going to cinema (very } \\
\text { high/high)§, }\end{array}$ & 31.2 & 41.4 & 44.0 & 47.79 & 56.8 & 57.6 & 35.0 & 39.4 & 47.39 & 25.0 & 43.0 & $<0.001$ & $<0.001$ & 0.085 \\
\hline $\begin{array}{l}\text { Trips to Guangdong (very } \\
\text { high/high)§ }\end{array}$ & 71.1 & 77.1 & 69.7 & 72.7 & 82.19 & 83.2 & 75.9 & 83.2 & $89.7-$ & 77.3 & 79.6 & 0.010 & 0.404 & $0.008^{* * *}$ \\
\hline $\begin{array}{l}\text { Trips to other provinces, } \\
\text { Mainland China (very high/ } \\
\text { high)§, }\end{array}$ & 37.3 & 45.6 & 47.8 & 43.1 & 63.5 & 64.19 & $50.6^{*}$ & 59.4 & $78.2^{* *}$ & $71.9^{* *}$ & 59.1 & $<0.001$ & $<0.001$ & $<0.001^{* * *}$ \\
\hline \multicolumn{15}{|c|}{ 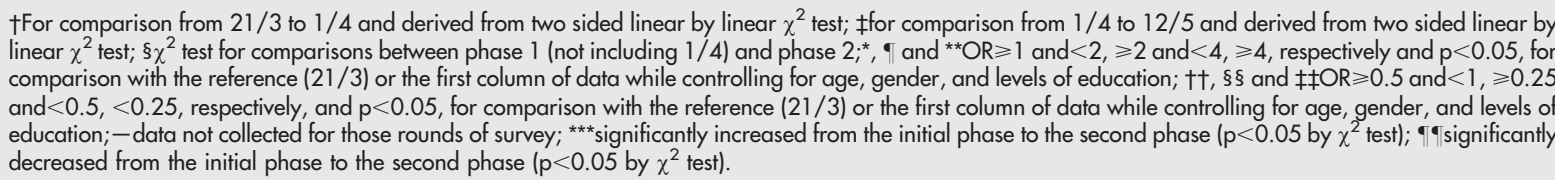 } \\
\hline
\end{tabular}

second phase. Over half of the respondents believed that environmental contamination was a mode for the disease transmission. An increasing number of respondents believed SARS to be curable in the initial phase $(\mathrm{p}<0.001)$ but the figure decreased in the second phase $(p<0.001)$ and conversely, a decreasing proportion of the respondents believed SARS to be fatal $(\mathrm{p}<0.001)$. Fewer respondents thought that SARS could be transmitted via aerosols $(\mathrm{p}<0.05$, table 1$)$ or SARS was fatal $(\mathrm{p}<0.05)$ in the second phase, as compared with the first phase; while the reverse is true for that "SARS could be transmitted via articles touched by SARS patients" $(\mathrm{p}<0.05)$ and that "SARS is curable" $(\mathrm{p}<0.05)$.

\section{Perceived susceptibility of contracting SARS}

The results are shown in table 1 . The trends of perceived susceptibility was not significant in the first phase and they declined in the second phase (self susceptibility: $4 \%$ on $21 / 3,12 \%$ on $1 / 4, p=0.124$ and decreased to $5 \%$ on $12 / 5$, $\mathrm{p}=0.038$; susceptibility of family members: $6.4 \%$ on $21 / 3$, $11.4 \%$ on $1 / 4, p=0.430$, and decreased to $1 \%$ on $12 / 5$, $\mathrm{p}=0.017)$. About $34 \%$ of the respondents felt "worried/very worried" about their own or their family members' contracting of the virus; the figure dropped sharply in the most recent survey ( $18 \%$ on $12 / 5, \mathrm{OR}<0.5$ and $\mathrm{p}<0.05)$. The percentage of respondents who feared that they would contract the virus in public places also declined in the second phase of epidemic (from $52 \%$ on $1 / 4$ to $36 \%$ on $12 / 5, p=0.001$ ). Respondents of the second phase were less likely to be concerned about contracting the virus as compared with those of the first phase (table 1).

\section{Perceived risk of transmission at different places}

Table 3 summarises the perceived risk of transmission in various public places. In general, the percentages of respondents perceiving a high chance of transmission in different places increased in the initial phase and decreased in the second phase (see table 2 ). In the initial phase, more and more respondents believed that travelling to Guangdong, China was associated with a "high/very high" risk of transmission $(71 \%$ on $21 / 3$ to $83 \%$ on $1 / 4, p=0.010)$, it was not significant in the second phase $(\mathrm{p}=0.404)$. The trend for perceived "high/very high" risk for visiting other provinces of China increased significantly all along the study period $(37 \%$ on $21 / 3,64 \%$ on $1 / 4$, and $72 \%$ on $12 / 5$, see table 2 ). In general, respondents in the second phase were less likely to perceive a high risk of contracting the disease in different venues, but they were more likely to perceive a high risk of contracting SARS in mainland China as compared with their counterparts of the first phase $(\mathrm{p}<0.05$, table 2$)$.

\section{Perceived efficacy of various means of prevention}

The results are shown in table 3. In the initial phase, there were significant increases in the percentage of respondents perceiving "wearing a mask" $(\mathrm{p}=0.034)$; "frequent hand washing" $(\mathrm{p}<0.001)$ and "home disinfection" $(\mathrm{p}=0.006)$ as effective means of prevention. These trends were, however, not significant in the second phase. Respondents in the second phase were more likely to believe that these measures were efficacious in preventing SARS $(p<0.05$, table 3$)$.

In the initial phase, significantly increasing percentages of respondents also believed "avoid going to different public places" (for example, public transportation and cinema, etc) to be useful means of prevention of SARS; in the second phase, these figures all significantly decreased to a lower level. The percentages of respondents who perceived "avoid visiting hospitals/clinics" (88\%), "avoid visiting China" $(83 \%)$ and "leaving Hong Kong for a while" $(20 \%)$ as "very useful/useful" means of prevention were fairly stable over time $(\mathrm{p}>0.05)$.

\section{Practice of preventive measures/behaviours}

In the initial phase, the reported frequencies of all preventive behaviours rose dramatically; in the second phase, decreasing trends were observed for these items (see table 4). However, percentages that indicated an intention to "avoid visiting China" (71\%) and "leave Hong Kong temporarily" (4\%) were stable over the study period (see table 4). In the first phase, the percentage of respondents practising different means of prevention were positively and highly correlated with the number of new cases and the total number of cases reported on the day preceding the survey. The correlation coefficients ranged from 0.809 to $0.965(\mathrm{p}<0.05)$ (table 5$)$. In the second phase, the correlations between preventive behaviours and 
Table 3 Perceived efficacy of means of SARS prevention

\begin{tabular}{|c|c|c|c|c|c|c|c|c|c|c|c|c|c|c|}
\hline & \multicolumn{10}{|c|}{ Date of interview } & \multirow[b]{3}{*}{ All } & \multirow{3}{*}{\multicolumn{3}{|c|}{ p Value†p Value $\neq p$ Value $\S$}} \\
\hline & \multicolumn{5}{|c|}{ Initial phase } & \multirow[b]{2}{*}{1.4} & \multicolumn{4}{|c|}{ Second phase } & & & & \\
\hline & 21.3 & 22.3 & 23.3 & 24.3 & 28.3 & & 8.4 & 11.4 & 24.4 & 12.5 & & & & \\
\hline \multicolumn{15}{|l|}{ Hygienic means } \\
\hline $\begin{array}{l}\text { Wearing a mask } \\
\text { (\% very effective/ } \\
\text { effective)§ }\end{array}$ & 79.5 & 78.8 & 72.2 & 75.8 & 84.0 & 84.9 & 86.1 & 85.8 & 80.0 & 80.8 & 81.7 & 0.034 & 0.171 & $0.037^{* \star *}$ \\
\hline $\begin{array}{l}\text { Washing hands } \\
\text { frequently (\% very } \\
\text { effective/effective)§ }\end{array}$ & 80.5 & 83.9 & 86.8 & 87.9 & $96.4^{* *}$ & $98.9^{* *}$ & $96.8^{* *}$ & $94.2^{\star *}$ & $96.4^{\star *}$ & $96.5^{\star \star}$ & 93.3 & $<0.001$ & 0.109 & $<0.001^{\star * *}$ \\
\hline $\begin{array}{l}\text { Disinfecting home } \\
\text { (\% very effective/ } \\
\text { effective)§ } \\
\text { Avoid going to different places }\end{array}$ & - & - & - & 69.7 & $83.4-$ & 88.19 & 86.19 & $88.4^{\bullet}$ & 88.4 - & $80.1^{*}$ & 74.7 & 0.006 & 0.267 & $0.013^{* * *}$ \\
\hline $\begin{array}{l}\text { Avoid going outside } \\
\text { (\% very useful/useful)§, }\end{array}$ & 62.8 & 55.8 & 61.5 & 51.5 & 72.8 & $75.1^{*}$ & 69.6 & 70.3 & 61.2 & 48.3 & 63.9 & $<0.001$ & $<0.001$ & 0.324 \\
\hline $\begin{array}{l}\text { Avoid crowded places } \\
\text { (\% very useful/useful)§, }\end{array}$ & 83.4 & 91.7 & 90.1 & 84.8 & 91.79 & $95.1^{* \star}$ & 91.89 & $95.5^{\star \star}$ & 90.2 & 81.3 & 90.2 & 0.010 & 0.002 & 0.426 \\
\hline $\begin{array}{l}\text { Avoid visiting hospitals/ } \\
\text { clinics (\% very useful/useful) }\end{array}$ & 85.7 & 83.3 & 86.8 & 74.2 & 94.6 ฯ & 89.2 & 86.1 & $96.1^{\star *}$ & 90.9 & 82.6 & 87.9 & 0.068 & 0.861 & 0.196 \\
\hline $\begin{array}{l}\text { Avoid using public } \\
\text { transportation (\% very useful/ } \\
\text { useful)§, }\end{array}$ & 41.0 & 40.4 & $57.1^{*}$ & 37.9 & 65.79 & 63.29 & 52.5 & 52.3 & 51.2 & 32.7 & 50.5 & $<0.001$ & $<0.001$ & 0.999 \\
\hline $\begin{array}{l}\text { Avoid going to work } \\
\text { (\% very useful/useful)§, }\end{array}$ & 19.2 & 19.9 & 30.0 & 16.7 & 40.8 & $49.7^{\star *}$ & 31.0 & 30.3 & 28.8 & 16.4 & 29.9 & $<0.001$ & $<0.001$ & 0.090 \\
\hline $\begin{array}{l}\text { Not allow kids to go to school } \\
\text { (\% very useful/useful)\&, }\end{array}$ & $1-$ & - & - & 33.8 & $68.0^{* *}$ & 64.99 & 58.99 & 62.19 & 58.39 & 39.0 & 57.0 & 0.028 & 0.001 & 0.587 \\
\hline $\begin{array}{l}\text { Avoid going to mainland } \\
\text { China(\% very useful/useful) }\end{array}$ & - & - & - & - & 82.2 & 84.3 & 80.4 & 85.7 & 89.6 & 76.7 & 83.1 & 0.610 & 0.986 & 0.741 \\
\hline $\begin{array}{l}\text { Leave Hong Kong temporily } \\
\text { (\% very useful/useful) }\end{array}$ & 19.5 & 16.0 & 16.7 & 18.2 & 25.0 & 21.6 & 21.5 & 21.9 & 17.8 & 15.7 & 19.6 & 0.240 & 0.183 & 0.956 \\
\hline \multicolumn{15}{|c|}{ 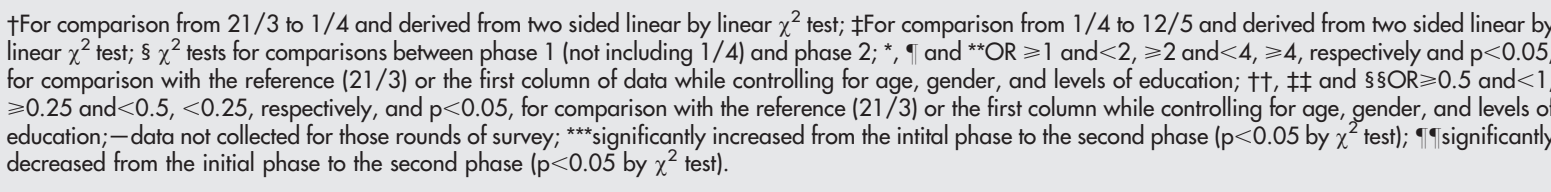 } \\
\hline
\end{tabular}

the number of new cases were non-significant, except for "avoid public transportation" $(r=0.894, p=0.04)$. The correlations with the total number of cases were either non-significant or negative ("avoid going outside", "avoid using public transportation", and "avoid going to work"), meaning that while the total number of cases kept rising in that phase, these "avoidance" behaviours became less common. Respondents were more likely to practice different types of preventive means in the second phase, as compared with the first phase $(\mathrm{p}<0.05$, table 4$)$.

\section{Attitudes related to wearing a mask}

Only a small percentage of the respondents would avoid someone wearing a mask ( $5 \%$ on 28 March and $7 \%$ on 12 May, $\mathrm{p}=0.858)$. Most of them $(95 \%)$ regarded it as a civic responsibility and indicated that they would wear a mask in public places as frequently as possible and that they would wear a mask in public places, if they had any flu-like symptoms (data not tabulated).

\section{Perceived severity of the disease}

Fewer respondents of the later surveys believed that the epidemic would last for less than three months (from $81 \%$ on 1 April to $65 \%$ on 12 May, $\mathrm{p}<0.001$ ). The percentage of respondents believing a high chance of occurrence of a large scale outbreak in Hong Kong increased in the initial phase $(p<0.001)$ and then became steady until 12 May $(12 \%$, $\mathrm{p}<0.001)$. Fewer respondents believed that the epidemic had largely been under control ( $27 \%$ on $21 / 3$ and $12 \%$ on 1 April, $\mathrm{p}<0.001)$ until 12 May $(73 \%, \mathrm{p}<0.001)$. Most of the respondents supported the quarantine policy $(85.8 \%)$ and believed that it was effective (over 90\%, p>0.05). A remarkably high proportion indicated that they would comply with that policy, had they had close contacts with SARS patients ( $91 \%, p=0.183$ from 1 April to 12 May) (data not tabulated).

\section{Factors associated with protective behaviours}

Variables reported in table 1 and table 2, together with the studied demographic variables, were used as input variables for the stepwise logistic regression models, and the relation between knowledge/attitudes and preventive behaviours were studied. Controlling for the date of interviews, female respondents (OR:2.017, 95\% CI: 1.293 to 3.314 ), those who believed that the virus could be transmitted via aerosols (OR:1.907, 95\% CI: 1.211 to 3.004 ), those working in hospitals (OR: 3.440, 95\% CI: 1.653 to 7.158 ), and those who perceived wearing a mask as an efficacious means of prevention (OR: $7.151,95 \%$ CI: 4.245 to 12.045 ) were more likely than others to wear a mask, while people who believed that SARS was under control in Hong Kong were less likely than others to report wearing a mask (OR: 0.378 , 95\% CI: 0.218 to 0.656 ).

Similarly, controlling for the date of interviews, those who were female (OR:1.841, 95\% CI: 1.062 to 3.194), older (OR: 2.294 for the 30-39 group, 2.267 for 40-49 and 2.477 for 5060 the group), who were "very worried/worried" about themselves and their family members being infected with SARS (OR:2.270, 95\% CI: 1.212 to 4.253 ) and perceived frequent hand washings to be efficacious in preventing SARS (OR: $31.996,95 \%$ CI: 13.876 to 73.781 ) were more likely than others to report frequent hand washing.

Those with an older age (OR: 3.065 for the 30-39 group, 2.504 for $40-49$ and 2.184 for $50-60$ the group), those who 
Table 4 Practice of preventive behaviours

\begin{tabular}{|c|c|c|c|c|c|c|c|c|c|c|c|c|c|c|}
\hline & \multicolumn{10}{|c|}{ Date of interview } & \multirow[b]{3}{*}{ All } & \multirow[b]{3}{*}{ p Valuet } & \multirow[b]{3}{*}{ p Valuef } & \multirow[b]{3}{*}{ p Value§ } \\
\hline & \multicolumn{6}{|c|}{ Initial phase } & \multirow[b]{2}{*}{8.4} & \multicolumn{3}{|c|}{ Second phase } & & & & \\
\hline & 21.3 & 22.3 & 23.3 & 24.3 & 28.3 & 1.4 & & 11.4 & 24.4 & 12.5 & & & & \\
\hline \multicolumn{15}{|l|}{ Hygiene Measures } \\
\hline Wearing a mask (\%)§ & 11.5 & 16.7 & 7.7 & 16.7 & $66.9^{* *}$ & $84.3^{* *}$ & $87.3^{* *}$ & $87.7^{* *}$ & $93.9^{* *}$ & $85.4^{* *}$ & 64.3 & $<0.001$ & 0.225 & $<0.001^{* * *}$ \\
\hline Hand hydiene (\%)§ & 61.5 & 66.7 & 63.7 & 80.39 & $94.1^{* *}$ & $95.1^{* *}$ & $93.7^{* *}$ & $94.2^{* *}$ & $94.5^{\star *}$ & $95.9^{* *}$ & 86.9 & $<0.001$ & 0.676 & $<0.001^{* * *}$ \\
\hline $\begin{array}{l}\text { Disinfecting home (\%)§, } \\
\text { Behaviours }\end{array}$ & - & - & - & 36.4 & 56.8 - & $69.4^{* *}$ & $72.2^{\star *}$ & $80.0^{\star *}$ & $83.5^{\star \star}$ & $73.1^{* *}$ & 70.1 & $<0.001$ & 0.022 & $<0.001^{* * *}$ \\
\hline $\begin{array}{l}\text { Avoid going } \\
\text { outside(\%)s, }\end{array}$ & 28.2 & 28.2 & 31.9 & 36.4 & 50.0 & $57.1 \oplus$ & $62.4^{* *}$ & $58.7-$ & 47.39 & 36.3 & 45.8 & $<0.001$ & $<0.001$ & $<0.001^{* * *}$ \\
\hline $\begin{array}{l}\text { Avoid crowded } \\
\text { places }(\%) \S, \uparrow\end{array}$ & 59.0 & 67.7 & 54.9 & 68.2 & 76.39 & $85.4^{\star \star}$ & 81.0 & $89.0^{* *}$ & $81.2 \uparrow$ & $69.6^{*}$ & 75.5 & $<0.001$ & 0.036 & $<0.001^{* * *}$ \\
\hline $\begin{array}{l}\text { Avoid visiting } \\
\text { hospitals }(\%) \S\end{array}$ & 59.7 & 63.5 & 52.7 & 62.1 & $73.4^{*}$ & $75.0-$ & 76.4 & $86.5^{\star *}$ & 79.99 & 68.6 & 71.8 & 0.001 & 0.892 & $<0.001^{\star * *}$ \\
\hline $\begin{array}{l}\text { Avoid using public } \\
\text { transportation(\%)§, }\end{array}$ & 14.1 & 15.4 & 16.5 & 24.2 & 26.6 - & 36.2 & $27.8 \bullet$ & 31.0 & 25.0 & 17.1 & 24.4 & $<0.001$ & 0.002 & $0.001^{* * *}$ \\
\hline $\begin{array}{l}\text { Avoid going to } \\
\text { work }(\%) \S,\end{array}$ & - & 2.6 & 2.2 & 4.5 & 6.1 & 8.1 & 7.7 & 7.3 & 5.5 & 1.2 & 4.9 & 0.002 & 0.018 & $0.038^{* * *}$ \\
\hline $\begin{array}{l}\text { Not allow kids to go to } \\
\text { school }(\%) \S \text {, }\end{array}$ & - & - & - & 12.5 & $35.7^{\star \star}$ & $38.1^{* *}$ & 31.0 & $36.7^{* *}$ & $39.6^{\star *}$ & 16.3 & 31.6 & 0.013 & 0.032 & 0.397 \\
\hline Avoid going to China (\%) & - & - & - & - & 64.5 & 69.6 & 72.2 & $75.5^{*}$ & $78.7-$ & 65.1 & 70.8 & 0.312 & 0.835 & 0.050 \\
\hline $\begin{array}{l}\text { Leave Hong Kong } \\
\text { temporarily }(\%)\end{array}$ & 5.1 & 2.6 & 3.3 & 6.2 & 2.4 & 5.4 & 2.5 & 3.2 & 6.1 & 2.9 & 3.8 & 0.340 & 0.876 & 0.524 \\
\hline \multicolumn{15}{|c|}{ 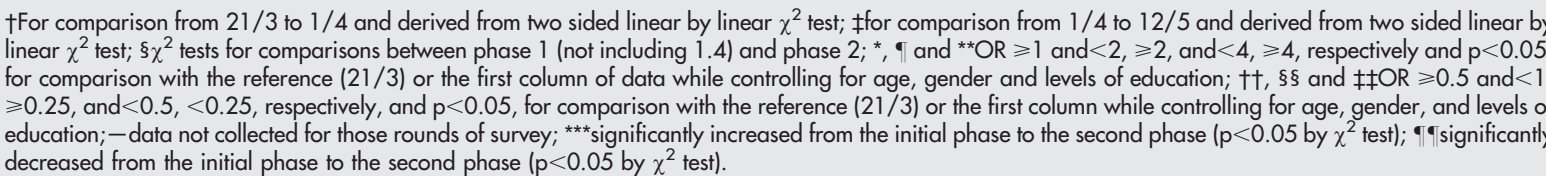 } \\
\hline
\end{tabular}

perceived disinfection of living quarters as "very effective/ effective" (OR: 17.282, 95\% CI: 9.731 to 30.691), those who much worried/worried about oneself and their family members being infected (OR: 1.922, 95\%: 1.245 to 2.967 ) were more likely than others to disinfect their living quarters after controlling for the date of interview. However, those who needed to travel to China on business were less likely than others to disinfect their home (OR: 0.521 , 95\% CI: 0.301 to 0.904$)$.

Similarly, those who were older (OR: 2.431 for the 30-39 group, 2.291 for $40-49$ and 2.387 for 50-60 the group), those with higher educational attainment (OR: 1.349 for between form 4 and form 7; OR: 2.261 for tertiary education), those who perceived very high/high risk for eating in a restaurant (OR: $1.975,95 \%$ CI: 1.296 to 3.009), and those who perceived avoiding crowded places as a "very effective/effective" measure (OR: $31.564,95 \%$ CI: 15.610 to 63.824 ) were likely to avoid crowded places after controlling for the date of interview and other confounders. Nevertheless, respondents who needed to travel to China on business (OR: 0.556, 95\%
CI: 0.332 to 0.931 ) or who worked at a hospital/clinic (OR: 0.523 , $95 \%$ CI: 0.274 to 0.996 ) were less likely to avoid crowded places.

\section{DISCUSSION}

The vast global consequence of SARS is not limited to the impact on those who were infected with the virus, but extends to everyone in the affected communities. Hong Kong, being among the first cities to deal with a major SARS outbreak when the aetiological agent was unknown, has experienced an inordinate amount of public distress. For instance, there was an inversion of percentages perceiving SARS would be curable and not fatal. Despite this, people in Hong Kong had been realistic in assessing their susceptibility to infection-less than $10 \%$ for most of the surveys and the trend was not significant even in the rising phase of the epidemic. Around 35\% of the respondents worried about contracting the disease, but similarly, the figures were stable over time. Few reported the intention of avoiding work or leaving Hong Kong temporarily. In other words, no panic

Table 5 Correlations between preventive behaviours and the number of new cases and the total number of cases reported the day before the survey

\begin{tabular}{|c|c|c|c|c|c|c|c|c|}
\hline \multirow[b]{3}{*}{ Preventive behaviours } & \multicolumn{4}{|c|}{ Initial phase } & \multicolumn{4}{|c|}{ Second phase } \\
\hline & \multicolumn{2}{|c|}{ Number of new cases } & \multicolumn{2}{|c|}{ Number of total cases } & \multicolumn{2}{|c|}{ Number of new cases } & \multicolumn{2}{|c|}{ Number of total cases } \\
\hline & $r^{*}$ & p Value & $r^{*}$ & p Value & $r^{*}$ & p Value & $r^{*}$ & p Value \\
\hline Wearing a mask & 0.965 & 0.002 & 0.939 & 0.006 & -0.362 & 0.549 & 0.408 & 0.496 \\
\hline Hand hygiene & 0.848 & 0.033 & 0.852 & 0.031 & -0.203 & 0.744 & 0.471 & 0.423 \\
\hline Disinfecting home & - & - & - & - & -0.512 & 0.460 & 0.378 & 0.435 \\
\hline Avoid going outside & 0.923 & 0.009 & 0.951 & 0.004 & 0.655 & 0.230 & -0.883 & 0.047 \\
\hline Avoid crowded places & 0.938 & 0.006 & 0.887 & 0.018 & 0.598 & 0.287 & -0.750 & 0.144 \\
\hline Avoid visiting hospitals & 0.893 & 0.016 & 0.809 & 0.051 & 0.091 & 0.884 & -0.324 & 0.595 \\
\hline $\begin{array}{l}\text { Avoid using public } \\
\text { transportation }\end{array}$ & 0.902 & 0.014 & 0.952 & 0.003 & 0.894 & 0.041 & -0.936 & 0.019 \\
\hline Avoid going to work & 0.918 & 0.028 & 0.937 & 0.019 & 0.779 & 0.121 & -0.906 & 0.034 \\
\hline
\end{tabular}

- Not calculated as data not available in the first three surveys; *derived from Pearson correlation coefficients. 


\section{Key points}

- To control SARS, both governmental and community efforts are required.

- The government should promote appropriate preventive behaviours by emphasising their efficacy and the high infectivity of the disease.

- Timely dissemination of accurate and comprehensive information would not cause panic, but would promote required prevention behaviours.

- Perceptions are important in determining preventive behaviours and systematic collection of perception and behavioural data should become part of the surveillance system on SARS. Results should be fed back to the policy makers and the public.

became evident in Hong Kong. The data thereby suggest that there was no widespread public panic even while the number of incident cases was increasing.

The prevalence of using a mask, adopting better hand hygiene, and disinfection of living quarters increased dramatically within a week (from 24 March to 1 April, $\mathrm{OR}>4, \mathrm{p}<0.01$ ). This was also seen in the adoption of other health measures promoted by the Department of Health, such as "avoid going to crowded places". In the first phase, these occurred in parallel with the increase in the number of new cases and the total number of reported cases. Transparency and timely dissemination of such data may therefore be very important in promoting preventive behaviours. It is important to note that despite the respondents' perception of lower risk of infection at different public places during the declining phase of the epidemic, the prevalence of infection control measures practiced (mask, disinfections, hand washing) remained at high levels (for example, $84 \%$ still wearing a mask on 12 May 2003). These are also shown by the non-significant correlation coefficients between the numbers of reported cases and using these preventive means in the second phase.

For a community to shape and change their responses in a rapid fashion, the availability of accurate information in a timely manner is a critical factor. It seems that the entire Hong Kong community had been responding to the number of newly reported cases and a number of critical events (see above). The results show that right from the starting phase (surveys of 21 to 24 March) of the epidemic, the overwhelming majority of the public have been closely following the matter, via multiple types of mass media. Television and newspapers have shown to be very common sources of information. As shown by our data, the internet was only used by a few respondents during the very early phase of the epidemic (3.3\%). The low use may be attributable to the fact that relevant information on the internet was still not widely available then (though later use of internet were expected to be more common). Traditional means of mass media are therefore still playing an important and irreplaceable part in the outbreak of emergent public health crisis, such as the SARS epidemic. The Department of Health and the hospital authority were holding press conferences on a daily basis during the study period; information about the number of cases, treatment, and mortality had therefore been disseminated in a thorough and transparent manner. The information has been reported in detail by the mass media, which in fact made up of the majority of all news reported during the time period. Experts were interviewed regularly. Therefore, the public were well supplied with the most updated information, which may account for the speed of their responses and the strong correlations between the number of reported cases and prevalence of preventive behaviours. With regard to the content of the mass media coverage, there was some inconsistency about the need of the use of mask, and the "droplet" theory was emphasised, in the very early phase of the epidemic. However, soon afterwards, consistent messages about how to use face masks, the need to wash hands frequently, avoidance of visiting crowded places, and the need to disinfect living places, etc, were clearly spelled out in the government announcements of public interests, as well as in other forms of media. Community campaigns of distribution of face masks and various types of posters enforcing the public health measures for SARS prevention have been launched by quite a number of community organisations as well. These may also explain why public health measures had been picked up so rapidly in a few weeks during the first phase of the epidemic (for example, frequent mask use increased from $11.5 \%$ on 21 March to 84.3\% on 1 April).

Perceived efficacy of the preventive measure, perceived seriousness of the problem in the community, perceived susceptibility, etc, in general, were predictors of preventive measures (such as mask wearing and hand hygiene). The findings are in line with factors described by the Health Belief Model. ${ }^{12}$ Women and older people were more likely to practice such measures than their male and younger counterparts. Education about efficacy of different means, together with the above mentioned data transparency, would therefore be expected to produce behavioural changes in a timely and effective manner.

The trends of risk perception of transmission in different places (for example, crowded places, in a lift, in restaurants, cinemas, public transportation) also closely followed the number of reported cases per day-rising in the initial phase and declining in the later phase of the epidemic. The perception of risk was related to behaviours such as avoidance of going outside or avoidance of going to public places. Our data show that people in Hong Kong were returning to their normal routine, with fewer people considering going to public venues as being a high risk activity and fewer people avoiding going out. Yet, there were still about $45 \%$ of the citizens who avoided going out. It is seen that more Hong Kong people were expecting that the epidemic would last longer than three months in Hong Kong, even in the second phase of the epidemic. The SARS epidemic severely affected every aspect of life and may have created long term health consequences.

Around $80 \%$ perceived a high risk of visiting Quangdong and increasing numbers perceived a high risk of visiting other provinces in mainland China (from $37 \%$ on 21 March to $72 \%$ on 21 May), while about $70 \%$ stated that they would avoid going to mainland China altogether. There were over 50 million cross border activities in 2002, ${ }^{13}$ the isolation of the two epidemics is, hence, virtually impossible. Surveillance, research, and education into effective prevention measures are of utmost importance.

The study is limited in several ways. Firstly, data are self reported and there may be some reporting bias. However, as trends were compared using the same questionnaire, internal consistency has been maintained. Secondly, the sample size for each round of survey is not large, although the total sample size was about 1400. Thirdly, details related to preventive measures, such as frequency and context of mask wearing were not asked, because of constraints in the length of the questionnaire. It, however, has the strength of using identical repeated cross sectional studies and covers the epidemic since its initial phase. 


\section{Policy implications}

- The epidemic of SARS in Hong Kong has been in decline since May 2003. Vital to the success was the introduction of adequate SARS prevention policies by Hong Kong Health Authorities during the epidemicthat is, reducing population contacts, improved hospital infection control, and more rapid hospital attendance.[11] The effectiveness of these preventive measures are largely determined by the perceptions and, more importantly, subsequent behavioural changes of the public. Transmission dynamic models of SARS agent show that increasing population contacts would increase the difficulty in eventually eradicating SARS in Hong Kong.[11] There is still a need to continue the current preventive measures and to avoid high population contact activities.

The epidemic of SARS in Hong Kong has been in the decline since May 2003. Vital to the success was the introduction of adequate SARS prevention policies by Hong Kong health authorities during the epidemic - that is, reducing population contacts, improved hospital infection control, and more immediate hospitalisation. ${ }^{14}$ The effectiveness of these preventive measures was largely determined by the perceptions and, more importantly, subsequent behavioural changes of the public. Transmission dynamic models of SARS show that increasing population contacts would increase the difficulty in eventually eradicating SARS in Hong Kong. ${ }^{14}$ Quarantine of household contacts of SARS was implemented on 10 April 2003..$^{15}$ The policies have been highly supported by the public. Equally important, public health measures such as a face mask use, home disinfection, and frequent hand washing were effective means for controlling SARS outbreak in the community settings ( $\mathrm{JL}$ et al unpublished data). It seems that the quarantine measures, together with a very high and consistent level of protective measures taken, accounted for the control of the epidemic in Hong Kong. This experience may prove useful to other affected countries in the future.

\section{CONCLUSION}

It is seen that community response to SARS, in terms of both attitudes and behaviours, can change dramatically. Depending on whether the epidemic was in its rising or its declining phase, the prevalence of preventive behaviours was related to the number of reported cases. Other factors such as perceived efficacy of prevention measures, perceived susceptibility, and perceived severity of the problem, etc, which are often described by the Health Belief Model, were also associated with the practice of preventive behaviours. Furthermore, although the community reacted rapidly and strongly to the development of the epidemic, no obvious panic was recorded by our data. Timely, accurate, systematic, and comprehensive dissemination of relevant information, (such as the number of new cases and efficacy of preventive measures), from authoritative sources may account for some of the above mentioned observations. It is of key importance in the control of the epidemic. It is seen that the public was actively seeking information and responded accordingly. The media, hence, also played an important part in the control of the epidemic. All affected countries should regard disclosure of information to be a means of control rather than a threat to the country.

It is also seen that for the SARS epidemic to be controlled in a country, both government and community efforts need to be taken into account. The quarantine policy, which should be an effective means of control, was strongly supported by the public in Hong Kong. The rapid increase of awareness and practice of preventive measures may have a strong contribution to the control of the epidemic in Hong Kong. Government efforts therefore should not only be limited to control of hospital transmissions, surveillance, and quarantine exercises, but should include promotion of public health preventive behaviours. Hence, the surveillance system should not only include the number of cases and contacts, but should also monitor changes in perceptions and behaviours by conducting systematic and serial surveys, such as the one of this study. It is also important that these surveys should be carried out from the initial onset of the epidemic and in a real time manner, have feedbacks to the policy makers and the community so that areas of concern could be addressed and relevant perception, behaviours be reinforced. Lastly, although the quarantine policy was well supported, the public was not satisfied with the governmental responses and were doubtful of its ability to control the epidemic. Proactive control policies may need to be developed by governments of different countries.

\section{Authors' affiliations}

J T F Lau, X Yang, H Tsui, J H Kim, Centre for Epidemiology and Biostatistics, School of Public Health, Faculty of Medicine, The Chinese University of Hong Kong, Hong Kong, China

\section{REFERENCES}

1 Lee $N$, Hui $D, W u A$, et al. A major outbreak of severe acute respiratory syndrome in Hong Kong. N Engl J Med 2003;348:1986-94.

2 Health Welfare and Food Bureau. Health, Welfare and Food Bureau SARS Bulletin (18 Apr 2003). http://www.info.gov.hk/dh/diseases/ap/eng/ bulletin0418.htm (accessed on $11 \mathrm{Jul}$ 2003).

3 World Health Organisation. Update 17-Travel advice-Hong Kong Special Administrative Region of China, and Guangdong Province, China. http:// www.who.int/csr/sars/archive/2003_2004_2002/en/ laccessed on 29 Jul 2003).

4 Hong Kong Department of Health. Battling SARS update/press release. http://www.ha.org.hk/sars/ps/pressrelease/index.html (accessed on 25 May 2003).

5 World Health Organisation. Cumulative number of reported probable cases of SARS. http://www.who.int/csr/sars/country/2003_2007_2009/en/ (accessed on 29 Jul 2003).

6 World Health Organisation. World Health Organization changes Hong Kong, Guangdong travel recommendations. http://www.who.int/ mediacentre/releases/2003/prwha2004/en/ (accessed on 29 Jul 2003).

7 Carter J, Park ER, Moadel A, et al. Cancer knowledge, attitudes, beliefs, and practices (KABP) of disadvantaged women in the South Bronx. J Cancer Educ 2002; 17:142-9.

8 Basuki E, Wolffers I, Deville W, et al. Reasons for not using condoms among female sex workers in Indonesia. AIDS Educ Prev 2002;14:102-16.

9 Rahman M, Shimu TA, Fukui T, et al. Knowledge, attitudes, beliefs and practices about HIV/AIDS among the overseas job seekers in Bangladesh. Public Health 1999;113:35-8.

10 Chan R, Khoo L, Goh CL, et al. A knowledge, attitudes, beliefs and practices (KABP) survey on HIV infection and AIDS among doctors and dental surgeons in Singapore. Ann Acad Med Singapore 1997;26:581-7.

11 Maticka-Tyndale E, Kiewying M, Haswell-Elkins M, et al. Knowledge, attitudes and beliefs about HIV/AIDS among women in northeastern Thailand. AIDS Educ Prev 1994;6:205-18.

12 Fisher JD, Fisher WA. Theoretical approaches to individual-level change in HIV risk behavior. New York: KluwerAcademic/Plenum, 2000.

13 Hong Kong Government Information Centre. Hong Kong residents departures by destination. http://www.info.gov.hk/censtatd/eng/hkstat/ hkinf/transport/transp8_index.htm (accessed on 27 May 2003).

14 Riley S, Fraser C, Donnelly CA, et al. Transmission dynamics of the etiological agent of SARS in Hong Kong: impact of public health interventions. Science 2003;300:1961-6.

15 Hong Kong Department of Health. Press release: household contacts of AP patients ordered to stay at home. http://www.info.gov.hk/dh/ap.htm (accessed on 27 May 2003). 